\title{
Degendering, millennials and organisational resilience
}

Many organisations were
already struggling from the
effects of global, social,
economic and environmental
crises before the COVID-19
pandemic struck. As a result,
sustainability and organisational
resilience have become the
focus of modern management
research and literature. Dr Hope
Witmer, of Malmö University
in Sweden, believes that to
successfully navigate the way
ahead, organisations need to
'degender' their structures,
practices and language, and
better understand the millennial
employees who will soon
comprise three-quarters of their
workforce.

he COVID-19 pandemic is the
latest in a series of social, econom and environmental crises to hit organisations worldwide. As a result, the focus for many organisational leaders is how they can meet pandemic-induced pressures in addition to comprehensiv addressing sustainability targets th address the triple bottom line of the people, and profit.

In response to the effects of such crises - with their resultant uncertainties surrounding health and safety, as well as employment and supply chain issues - organisations are being forced to think and act in new ways. Sustainability concerns and organisational resilience the ability of an organisation to anticipate, learn from, and quickly adapt to sudden change and disruption, as well as to new conditions - has become a key focus for


Dr Hope Witmer of the Department of Urban Studies at Malmö University in Sweden is a specialist in organisations and leadership. She is particularly interested in researching the topic from a resilience, learning, sustainability and gendered

DrWitmer believes that sustainable solutions to the problems that organisations currently face can be found and make equal use of the perspectives of all their employees. In her most recent work, she argues that the current crises can be addressed by the 'degendering' of organisational power structures and a better understanding of millennials in the workplace - men and women who have reached young adulthood in the early 21 st century. Experts predict that this cohort will form $75 \%$ of employees by 2025 .

DEGENDERING ORGANISATIONS DrWitmer argues that organisations have historically been constructed as "primarily male, hierarchical, with command-and-control styles of leadership". In this way, organisation - and management consultants have typically placed a high value on normative masculine characteristics such as strength, decisiveness, rationality, and emotional detachment.

Despite best intentions and the adoption of regulatory practices to mainstream gender equality, $\mathrm{Dr}$ Witmer finds that what appears as men's and women's interests and concerns not being regarded equally is symptomatic of organisational practices that continue to feature gendered power structures, practices, and thereby organ

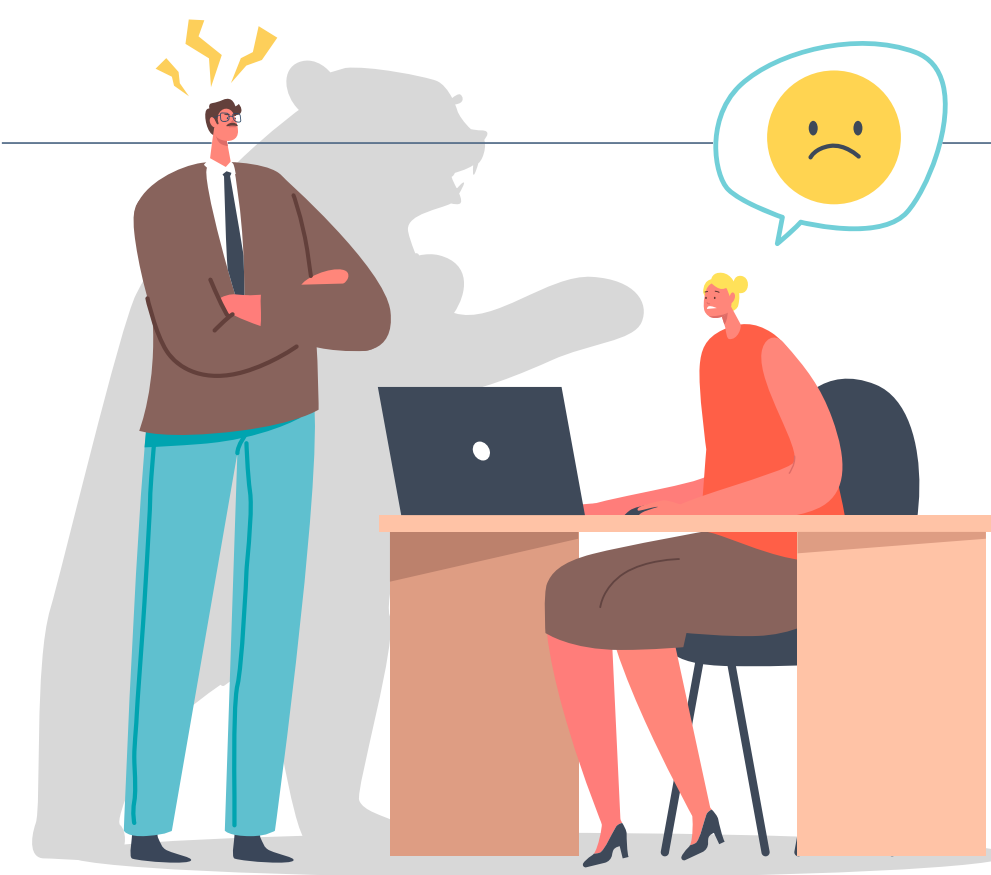

DrWitmer explains: "Organisational Dr Witmer explains: "Organisational
resilience is enacted during times of resilience is enacted during times of grn to no whative gasculine practices of rationality and reason to address 'tough' problems, thereby marginalising normative feminine practices of collaboration, learning, and creating a safe emotional environment which are equally crucial to organisational resilience." Resilience thrives best "in contexts of shared power, decentralised decision-making, and team-based or network structures",

aspects which are associated with ormative feminin practices.

DrWitmer has developed a Degendering Resilience (DOR) model

to help analyse the gendered power constructions that inhibit organisationa resilience. She explains: "In this model, power structures and roles would be analysed based on how resources are used and the variety of voices included in collaborative and innovative problemsolving, contributing to a gender-equal, inclusive construction of organisationa resilience."

She adds: "The purpose of the DOR Model is to expose patriarchal structures and power mbalances that perpetuare qupresion and suppress resilint with hes the ric nts accordance organisations. By exposing gendered practices, power imbalances and of ron incorporated without gendered distinctions weighting their value."

\section{MILLENNIAL ATTITUDES}

DrWitmer further believes that organisations need a better workplace - employees nows in the ages 21 and 35 - particularly because

Organisational practices continue

to feature gendered power

structures, practices, and language As DrWitmer explains, hich inhibit inclusivity and thereby that millennials value

organisational resilience. and "look to individual mentors for their employees from other generations.

Like any generation, millennials share a particular world view and set of values, beliefs, needs, and attitudes. Not only does this cohort demonstrate a more gender-fluid perspective as compared to typical binary definitions of gender, they also share a greater commitment to equity and sustainability. DrWitmer also finds its members look beyond economic gain from employment and seek socie contribution and a better work-life In addition, they share a distrust of leadership training and development rather than corporate structures participants were "critical of hierarchical structures and distrustful of power that was limited to an individual versus a

Discussions regarding how millennial perceptions are formulated were analysed based on the three categories of DrWitmer's DOR model, that is: power structures, actions, and language.

Among many insights, the results ecognised the influence of national and practices". In addition, group 




perceived power to affect change. For not reflective of global, which were perspectives. This was problematic by creating dissonance for those factors (what society defines as masculine or feminine) are linked to the systemic design of the organisation, although often embodied in the millennials' following examples.

Other millennials reported that even though employees had equal did not have equal sup moant that they where much of the work is still done by women. Due to this lack of alignment of societal and workplace norms, they experienced the dual pressure home. As Dr Witmer reports: "They viewed themselves as global citizens, yet they were still bound, and at times marginalised, by the norms of their national culture."

Even when organisations had inclusive gender equity policies, employees seat at the table ", however, it was hard for them to sustain power and they were such as minute-taking or arranging social example, some millennials reported that organisational policy reflected regarded themselves as ghose who and wanted to see policies that align with global perspectives of equality.

It is important to highlight that gendered experience based on their sex, as in the opportunities in the workplace, societal of increased work responsibilities in addition to primary responsibilities at reported that women might be given "a events. In addition, though employees said that their organisations emphasis equal representation based on mert, females stil had to "act male" to or pushing and using power", as stated by one inteniewee.

Millennial males reported being frustrated that they felt "guilty by
association" with masculine-coded organisational behaviour. One

to find innovative, inclusive and they face. The solutions to the problems have moved towards more inclusive language, DrWitmer's research suggests that there is still a "disconnect between espoused values and actual practices". As a result, organisations need to look at their systems, practices, and power dynamics to identify barriers to inclusivity.

DrWitmer's study of millennial workplace - is highly significant for organisational leaders who need to are to be resilient in response to longterm crises such as climate change along with short-term crises such as COVID-19. Among the most important insights: millennials are committed to social values and equity, but not necessarily share "a more equalitarian gender social issues such as sustainability. In addition, they have a more integrated incorporates masculine-coded aspects of resilience (e.g., strategic, directive,

Resilience thrives best "in contexts of shared power, decentralised decision-making, and team-based or network structures".

interviewee said: "I don't want to be put rational) with feminine-coded aspects of in the same category as those old white resilience (e.g., collaborative, reflective, empathetic) as equally valued in both proximity or distance to hegemonic

DrWitmer concludes that millennials feel trapped between two conflicting $\begin{array}{ll}\text { narratives: what they consider politically } & \text { Dr Witmer recommends organisational } \\ \text { correct and how the power dynamics in } & \text { policies and practices "that deconstruct }\end{array}$ She explains: "What emerged was a motivated cohort that felt empowered as individuals to bring about change for organisational context, they felt frustrated cherspectives of on gen gender-weighted CONCLUSION

times of crisis, organisational leaders inequitable practices and co-create more agile structures, practices and narratives for sustainable and resilient organisations". She explains: "For organisations to be resilient, there is acilits ingstemic processes that . to constructive, adaptive organisationa of stress and pressure. It is thereby important to incorporate these qualitities "sustanability on a systemic less." employees - the largest cohort in the gendered perspective of resilience that and powerless to effect organisational

Dr Hope Witmer

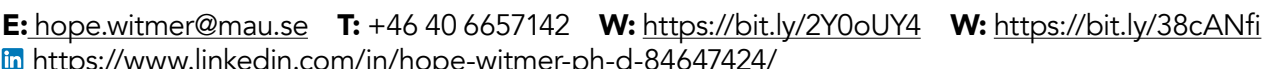
incorporate multiple perspectives if they perspective" and are committed to a sustainable future. However, within the responses when under high levels

\section{Research Objectives}

Dr Hope Witmer researches organisational resilience with a particular focus on sustainability leadership and power dynamics.

\section{Detail}

\section{Bio}

Dr Hope Witmer is an Associate Professor of leadership and focuses on resilience, power and gender constructions, in relation to sustainability leadership, organisational change, innovation and inclusion. She is the Director of the

Funding University, Swede

\section{Jif mamó \\ UNIVERSITY}



\section{References}

Witmer, H. (2021). Entrapment Between Narratives: the millennial voice and degendering organisational resilience. Frontiers in Sustainability, Vol. 1. Available at: https://doi. org/10.3389/frsus.2020.620903

Witmer, H. (2019). Degendering Organisational Resilience: the Oak and Willow against the wind. Gender in Management,
34(6). Available at: https://doi.org/10.1108/GM-10-2018-0127

Scholten, C., Witmer, H. (2017). The opaque gendered lens - barriers to recruitment and career development. Gender in Management, 32(1). Available at: https://doi.org/10.1108/ GM-09-2015-0082

\section{Personal Response}

Following your research, do you regard the crises which organisations currently face as a threat or an

II Resilience is an iterative process based on mission and built on learning and innovation, thereby any crisis is a threat and opportunity. In the recent crisis, wellwhile small businesses, start-ups, gig workers, those with the least power, voice, and resources, have experienced this crisis as primarily a threat. Organisational resilience is not solely measured by economic gain but includes societal contribution and shared power. Thereby, it is important th post-COVID narratives to assure that definitions of resilience
are not limited to economic success and power.



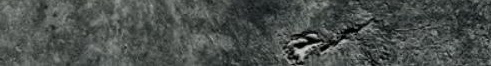

